\title{
Past, Present, and Future of Fruit Germplasm Exploration
}

\author{
Kim E. Hummer \\ USDA, ARS, National Clonal Germplasm Repository, 33447 Peoria Road, Corvallis, OR 97333-2521
}

\begin{abstract}
The fruits of the earth have healed, nurtured, and intrigued humanity throughout history. Cultivated fruit species have complex genome that will continue to require the input of novel genetic resources. Prospecting for wild fruit species will continue. The global nature of science and commerce will drive the demand to expand available genetic resources for fruit improvement. New technologies will enable future explorers to reach remote sites and species. Recent advances, such as geopositioning and remote-communication devices, will be used to a greater degree for targeting specific collection sites and documenting records of origin. The sovereignty of countries over their plant genetic resources, as specified by the Convention on Biological Diversity and the International Treaty on Plant Genetic Resources for Food and Agriculture, will continue to be a cornerstone for negotiating bilateral agreements and plant exchange. Although this could be considered a limitation to plant exploration in some situations, global strategies now in conceptual infancy will be developed to encourage and support ex situ preservation and continued plant exchange for long-term conservation and humanitarian benefit.
\end{abstract}

\section{ADMINISTRATIVE ASPECTS}

Organized plant collection began with the Pharaohs of ancient Egypt, who by 2000 BCE brought back exotic trees and plants in their foreign conquests (Janick, 2007). The Ancient Greek, Roman, and Chinese civilizations were the first to document the medicinal value of plants. Until recently, human attitudes toward plant collection have not changed appreciably from the archaic concept of "take whatever you want." The concept of plant genetic resources was originally defined as any wild weed (plant) growing somewhere in the world that could be freely taken and brought back to the collector's home. Exotic plants became the building blocks of markets and economy, and crop development enriched only the collector and his/her state. Empires were built based on plant materials removed from other countries (Janick, 2007). World leaders throughout the past $2000+$ years invested great amounts of human and fiscal resources to develop genetic resources into useful products. The geographic discovery of the extent of our globe could be thought of as a by-product of the desire for new resources, including germplasm from far-away ports.

Now the world is small and easy to traverse. Since the Convention on Biological Diversity (CBD) was established in 1993 (CBD, 2005), plant genetic resources are redefined as the "sovereign property" of the country in which they are found. This new interpretation initiated new concepts and requirements that shape the future of plant exploration and exchange. Under these new regulations, plant material can no longer be removed arbitrarily without due consideration of farmers, land owners, or sovereign territories.

New regulations. The $\mathrm{CBD}$ changed the definition of the implied "value" of germplasm. This treaty, in consort with the International Treaty for Plant Genetic Resources (2005), which came into force on 1 July 2004, signed by 79 countries, provides the legal framework for this new era of plant collection

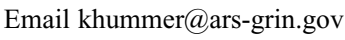

and exchange. Countries must now prepare bilateral agreements with the prior informed consent of both parties concerning the specific items and times of plant exploration or exchange specifically for the 64 crops of the Annex 1 list. Considerations for immediate, associated mutual benefits are another component of exchange agreements. The sharing of benefits later, for developed germplasm and intellectual property rights, is also initially defined. These new requirements were developed to provide for farmers, breeder, and country rights of this plant material.

The future of genetic resource exchange somewhat resembles trading on the stock market as countries negotiate for future market shares and speculate on the future worth of potentially valuable developed plant products.

\section{PHYSICAL ASPECTS}

Planning. The early explorers were the de facto cartographers of the world. They developed the maps that subsequent explorers have used to determine route and direction.

Technological advances now enable explorers to sit at home or in the office, connect with the Internet, and, through the use of geological positioning devices, plan a collecting route that most likely will contain targeted species. Maps overlain with topographical features, climate zones, soil types, and other readily available geographical data can direct the collector. Global positioning devices are inexpensive, light, and easy to use in the field for precise locality determination. Collecting routes uploaded daily to portable data storage devices, and satellite phones are used to monitor collecting progress. New geographic information systems or spatial mapping software provide a priori analyses of collection routes to maximize the possibility of success in expedition planning. One such program, Diva (IPGRI, 2006), was developed for genetic resources data specifically for use with genebank data such as that available through national or international documentation systems. Diva produces maps of sites where species were observed or collected and of the pattern of distribution of biological diversity. Diva can also identify areas with complementary levels of diversity and extract climate data for accession points.

Personal aspect. The hardships of early explorers were great. For example, the vigorous, young Frank Meyer disappeared from a steamer on the Yangtze River during his final plant exploration trip in 1918 (Cunningham, 1984). Although most of the hardships now are not as intense as in previous decades, plant explorers still face language, cultural, sustenance, and travel challenges. Personal safety will continue to be at risk in politically charged areas.

Collection challenges into the future. Once the expedition reaches a collection location, difficulties may exist in finding the desired species. Intrusion of human development or in situ ecological changes may reduce rare species with limited distribution or diversity within populations of more widely distributed species. Sometimes fruits and seeds are found only at the top of tall trees. In the past, younger individuals were contracted to climb trees to obtain seeds for collections. In the future, unmanned air vehicles, such as the "dragon eye," may scout areas or regions for target species. Such devices could provide photographic recordings of species distribution. Sensors may remotely register contents of specifically desirable natural products and may map compound-rich locations from the air. Hand-released "spider" robots may be deployed to the tops of trees or high ridges to collect and retrieve inflorescences or fruit.

Data management. Recorded information of germplasm collections began with the temple drawings and writings found on tombs and pottery of ancient monarchs and leaders. Paintings of the great masters of the Renaissance, such as Caravaggio, Rafael, and others, recorded evidence of New World plants brought to Europe (Janick, 2004). Data and images of genebank collections are established in modern information systems. The present challenge is to format data for ease of accessibility to each link. Data entry protocols are being systemized, and 
taxonomic ontology is becoming standard as the need for global data searches is realized.

\section{CONCLUSIONS}

The unrestricted collection of wild plant material assisted the development of civilizations over the millennia of recorded history. Times have changed, and recent international agreements and treaties now define the sovereignty of countries over their plant genetic resources. Nevertheless, continued exchange of available genetic resources will be needed for crop and fruit improvement, and plant expeditions will continue. The need for countries to obtain plant genetic resources within their own borders for plant-exchange purposes will increase. Bilateral agreements and arrangements for mutual benefit will ensure the continuation of exploration activities. Geopositioning systems, remote-communication devices, and robotics will enable future explorers to reach sites and species that are presently inaccessible. These new technologies will be used to a greater degree for targeting specific collection sites and documenting records of origin.

\section{Literature Cited}

CBD. Convention on Biological Diversity. 2005 United Nations Environment Program. 6 Dec. 2005. http://www.biodiv.org/default.shtml.
Cunningham, I.S. 1984. Frank N. Meyer: Plant hunter in Asia. Iowa State Univ. Press, Ames, Iowa $317 \mathrm{pp}$.

IPGRI. International Plant Genetic Resources Institute. 2006. GIS software to explore and conserve genetic resources. 27 Mar. 2006. http://www.ipgri.cgiar.org/regions/americas/ programmes/gissoftware.htm.

International Treaty on Plant Genetic Resources for Food and Agriculture. 2005. Commission on Genetic Resources for Food and Agriculture. 6 Dec. 2005. http://www.fao.org/ag/cgrfa/ itpgr.htm.

Janick, J. 2004. Caravaggio's fruit: a mirror on Baroque horticulture. Chronica Hort. 44(4):9-15.

Janick, J. 2007. Plant exploration: from Queen Hetshepsut to Sir Joseph Banks. HortScience 42(2):191-196 (published in this workshop). 